\title{
In sacco digestion kinetics of palm kernel expeller (PKE)
}

\author{
F.N. DIAS ${ }^{1}$, J.L. BURKE ${ }^{1}$, D. PACHECO ${ }^{2}$ and C.W. HOLMES ${ }^{1}$ \\ ${ }^{1}$ Institute of Veterinary, Animal and Biomedical Sciences, Massey University, Palmerston North, New Zealand \\ ${ }^{2}$ AgResearch Limited, Grasslands Research Centre, Tennent Drive, Palmerston North, New Zealand
}

F.N.Dias@massey.ac.nz

\begin{abstract}
Palm kernel expeller (PKE) is imported into New Zealand and fed to ruminants grazing pasture, but very little data exist on its rumen digestion characteristics when fed in conjunction with grass. The results from in sacco digestion of dry matter (DM) or crude protein (CP) showed that PKE has significantly lower soluble protein (fraction A: $25.8 \%$ and $35.5 \%$ ) than pasture $(41.4 \%$ and $52.3 \%)$ and the potentially degradable protein (fraction B) for PKE (61\% and $60.2 \%)$ was significantly greater than that of pasture $(54.5 \%$ and $46.5 \%)$. The degradation characteristics of mixed PKE plus pasture $(\mathrm{P}+\mathrm{PKE})$ were intermediate to those of the two feedstuffs alone. The lag phase (L) was significantly different for each of the pasture and PKE mixtures, either in the $\mathrm{DM}$ or $\mathrm{CP}$ degradation. The rate of degradation $(k)$ for DM was not different between feeds (around 12.5\%/h) in Experiment 1, but they were slower for PKE, in Experiment 2. The type of diet provided to the cows affected the estimated lag phase and $\mathrm{CP}$ degradation rates; this could indicate that adaptation to PKE is necessary to achieve its potential as a supplement for grazing cows.
\end{abstract}

Keywords: digestion kinetics, crude protein, dry matter, palm kernel expeller, pasture

\section{Introduction}

The dairy system in New Zealand is based on grazed pastures, but when short term pasture deficits are created (e.g. dry weather conditions during summer) or when lactations are extended, the use of supplementary feed is necessary. During the last 5 years, palm kernel expeller (PKE) has reached great popularity as a source of supplementary feed among farmers wishing to fill those short term deficits, particularly because of its low price compared with other supplements.

PKE is a by-product from the palm oil industry produced after the extraction of the oil from the kernel of the palm Elaeis guineensis (Jacq.). According to a report from MAF (2007) more than 362,000 tonnes of PKE were imported into New Zealand in 2006/07. The few scientific reports about PKE have shown that its chemical composition can vary significantly, and the dry matter (DM) contains between 158 and $194 \mathrm{~g} / \mathrm{kg}$ of crude protein $(\mathrm{CP}), 685$ and $801 \mathrm{~g} / \mathrm{kg}$ of neutral detergent fibre (NDF) and 78 and $128 \mathrm{~g} / \mathrm{kg}$ of fat (Moss
\& Givens 1994; Hindle et al. 1995; O'Mara et al. 1999). These authors also reported that PKE organic matter digestibility (OMD) ranges between 650 to $750 \mathrm{~g} / \mathrm{kg}$ DM when measured either in vitro or in vivo. However, there is some evidence that the rate of degradation in the rumen of the main PKE components, fibre and protein, is very slow (Hindle et al. 1995; Woods et al. 2003).

PKE differs from other supplements used in New Zealand farms and a better understanding of its degradation characteristics in the rumen is necessary to make informed decisions about its inclusion as a supplement for dairy cows grazing temperate pastures. Therefore, the objective of this research was to determine the DM and CP digestion kinetics of PKE and to compare them with pasture (ryegrass and white clover).

\section{Methods}

The rumen digestion characteristics of PKE alone or in combination with pasture were measured in two separate in sacco experiments. In both experiments, fresh spring pasture samples were cut with clippers to approximately $5 \mathrm{~cm}$ above the ground and stored in a freezer $\left(-20^{\circ} \mathrm{C}\right)$ until its preparation for incubation in sacco according to the methods described by Burke et al. (2000). Briefly, frozen pasture samples were minced to achieve a particle size distribution similar to that of pasture chewed by a ruminant. The two PKE samples used in each experiment were collected from a commercial feed mill (Premier Stock Feeds Limited NZ) and stored in a dry place until incubation.

The DM content of the pasture and PKE samples was determined by drying the samples in a forced-air oven at $65^{\circ} \mathrm{C}$ for $48 \mathrm{~h}$. Samples of the minced pasture were analysed for chemical composition by near infrared reflectance spectroscopy (NIRS, FeedTech, Palmerston North). PKE samples were ground $(1 \mathrm{~mm})$ and analysed by wet chemistry for ash (942.05), CP (968.06) and lipid (991.36) (AOAC, 2005). NDF and acid detergent fibre (ADF) were determined as described by Robertson \& Van Soest (1981).

Two non-lactating Holstein-Friesian cows fitted with rumen cannulae were used for both in sacco experiments. Cows were fed at maintenance level twice a day, with half of the diet being offered before $0900 \mathrm{~h}$ and the other half offered after $1700 \mathrm{~h}$. 


\section{In sacco}

\section{Experiment 1}

In this experiment cows received a diet composed of lucerne chaffage (Fibre Fresh Feeds of New Zealand) plus PKE at 75:25\% as fed basis. Dacron bags, each containing approximately $5 \mathrm{~g}$ total dry weight of either pasture alone, PKE alone or a 50:50 mix (DM basis) of pasture plus PKE $(\mathrm{P}+\mathrm{PKE})$ were incubated in three separate runs, over 7 days. In the first incubation, Dacron bags containing just pasture were incubated in Cow A whilst Dacron bags containing only PKE were incubated in Cow B, and this allocation was reversed between the cows during the second incubation. In the third incubation Dacron bags containing $50 \%$ of pasture and $50 \%$ of $\mathrm{P}+\mathrm{PKE}$ were incubated in both cows. Triplicate bags of each feed were removed after 2, 4, 6 , $8,12,24$ and $72 \mathrm{~h}$ of incubation and were hand-washed thoroughly with cold tap water until the rinse water was clear. Three bags of each feed ( 0 -h samples) were washed without incubation in the rumen.

\section{Experiment 2}

In this experiment cows received a diet composed of lucerne chaffage only. Dacron bags containing approximately $5 \mathrm{~g}$ dry weight of pasture or $6 \mathrm{~g}$ dry weight of PKE were incubated at the same time in both cows. Duplicate bags of each feed were removed after 2 , $6,12,24$ and $72 \mathrm{~h}$ of incubation and were hand-washed as described above.

The amount of material incubated was determined from DM percentage and wet weight measured into Dacron bags prior to incubation. Following removal from the rumen and after washing, all bags were dried in a forcedair oven at $85^{\circ} \mathrm{C}$ for $48 \mathrm{~h}$ and weighed to determine residual DM in the bags. The pasture residues were analysed for CP determination by NIRS, while the CP content of $\mathrm{PKE}$ and $\mathrm{P}+\mathrm{PKE}$ residues were analysed using wet chemistry (968.06, AOAC 2005). The amount of $\mathrm{CP}$ in the residues was calculated by multiplying the dry weight of each bag by the CP concentration of the feed residues. Residual amounts were expressed as a percentage of the initial DM and CP incubated in each bag, and the degradation was calculated as 100 minus the residual DM or $\mathrm{CP}$.

\section{Digestion kinetics}

The ruminal kinetics of DM and CP disappearance of each feed and cow were estimated by fitting curves to the DM and CP disappearance data using a non-linear leastsquare procedure (PROC NLIN; SAS 2003). The curve selected for parameter estimation was the exponential decay curve with or without lag described by Lopez et al. (1999), which defines the degradation of the feeds (D) at time $t$ according to:

$$
\mathrm{D}_{\mathrm{DM}, \mathrm{CP}}=\mathrm{A}+\mathrm{B}\left(1-\mathrm{e}^{-k(t-\mathrm{L})}\right) \quad \text { (Eq. 1) }
$$

where $\mathrm{A}$ is the measured soluble fraction (\% DM, CP) from the 0 -h hand-washed samples; $\mathrm{B}$ is the potentially degradable fraction ( $\% \mathrm{DM}, \mathrm{CP}) ; k$ is the fractional disappearance rate $(\% / \mathrm{h}) ; t$ the time of incubation (h) and $\mathrm{L}$ is the lag phase $(\mathrm{h})$, period of time during which no digestion occurs or digestion occurs at a slow rate (McDonald 1981). For the no-lag models, $\mathrm{L}=0$.

Effective degradability (ED) was calculated as:

$$
\mathrm{ED}=\mathrm{A}+(\mathrm{B} \times k) /\left(k+k_{p}\right) \quad(\text { Eq. } 2)
$$

where $\mathrm{A}, \mathrm{B}$ and $k$ are the parameters estimated from fitting Eq.1, assuming a rumen outflow rate $\left(k_{p}\right)$ of $6 \%$ / h (Ørskov \& McDonald 1979).

\section{Statistical analyses}

To evaluate the fit of each model (with or without a lag phase) to the DM and CP disappearance data measured during the incubations, several statistics were calculated, including root of mean square prediction error (RMSPE), Bayesian information criteria (BIC) and Akaike's information criteria (AIC). In all cases, the model including lag provided a better fit (smaller RMSPE, BIC and AIC values) to the measured disappearance data and therefore these analyses are presented here.

The parameters of the non-linear models fitted for each feed were obtained using the observations (means of triplicates and duplicates from Experiments 1 and 2, respectively) from both cows (Table 2). The coefficient of determination $\left(\mathrm{R}^{2}\right)$ for all fitted curves was higher than 0.97. Means \pm standard deviation of the observed DM or CP disappearance for the feeds tested in both experiments are presented in the Figures 1 and 2, together with the fitted curves.

\section{Results}

The chemical composition of pasture and PKE are shown in Table 1. The pasture samples used in both experiments had a metabolisable energy (ME) content of 11.4 MJ/kg DM with a high CP content ( $24 \mathrm{~g}$ of CP/100 g DM) and low soluble sugars and starch content.

The sampled PKE contained $16 \% \mathrm{CP}$ with most of the energy coming from the fibre (NDF) and fat fractions and the soluble sugars and starch fraction being small. The chemical composition of $\mathrm{P}+\mathrm{PKE}$ samples was calculated as the arithmetic mean of PKE and pasture chemical composition analyses.

\section{DM digestion kinetics}

The in sacco DM disappearance data are illustrated in Figure 1 and the estimated DM fractions and degradation parameters are summarised in Table 2. The percentage of DM released during hand washing of unincubated samples (i.e. soluble DM; fraction A) was 
Table 1 Chemical composition ( \pm standard deviation) of the pasture and palm kernel expeller (PKE) used for measurement of digestion kinetics

\begin{tabular}{lcc}
\hline Item & Pasture $^{1}$ & PKE $^{2}$ \\
\hline Dry matter (\%) & 13.7 & 97.2 \\
\cline { 2 - 3 } Crude protein & $24.0 \pm 0.65$ & $160.0 \pm 0.76$ \\
Neutral detergent fibre & $51.9 \pm 2.47$ & $70.3 \pm 4.78$ \\
Acid detergent fibre & $25.9 \pm 0.57$ & $39.3 \pm 2.24$ \\
Fat & $4.0 \pm 0.06$ & $9.0 \pm 0.52$ \\
Soluble sugars and starch & $3.0 \pm 1.02$ & - \\
Ash & $10.8 \pm 0.02$ & $4.1 \pm 0.67$ \\
\hline
\end{tabular}

${ }^{1}$ Analysed using near-infrared reflectance spectroscopy - FeedTech, AgResearch Grasslands - Palmerston North

${ }^{2}$ Analysed using wet chemistry - AOAC (2005)

Table 2 Mean dry matter (DM) and crude protein (CP) degradation characteristics of pasture, palm kernel expeller (PKE) and pasture plus PKE (P+PKE) defined as soluble fraction $(A)$, potentially degradable fraction $(B)$, undegradable residue $(U)$, fractional disappearance rate $(k)$, lag phase $(L)$ and effective degradability (ED).

\begin{tabular}{|c|c|c|c|c|c|c|}
\hline \multirow[b]{2}{*}{ Feeds } & \multicolumn{6}{|c|}{ Parameter estimates } \\
\hline & $\begin{array}{c}A \\
(\%)\end{array}$ & $\begin{array}{c}\mathrm{K} \\
(\% / \mathrm{h})\end{array}$ & $\begin{array}{c}\mathrm{B} \\
(\%)\end{array}$ & $\begin{array}{l}\mathrm{L} \\
(\mathrm{h})\end{array}$ & $\begin{array}{c}U^{1} \\
(\%)\end{array}$ & $\begin{array}{l}E D^{2} \\
(\%)\end{array}$ \\
\hline \multicolumn{7}{|c|}{$\begin{array}{l}\text { Experiment } \mathbf{1} \text { - cows fed lucerne chaffage with PKE } \\
\text { DM kinetics for: }\end{array}$} \\
\hline Pasture & 41.4 & 12 & 54.7 & 0.9 & 3.9 & 78 \\
\hline PKE & 24.8 & 13 & 61.4 & 5.0 & 13.7 & 66 \\
\hline Pasture + PKE & 38.8 & 12 & 53.1 & 2.9 & 8.1 & 74 \\
\hline $\begin{array}{l}\text { CP kinetics for: } \\
\text { Pasture } \\
\text { PKE } \\
P+\text { PKE }\end{array}$ & $\begin{array}{l}52.3 \\
37.8 \\
45.4\end{array}$ & $\begin{array}{l}34 \\
10 \\
11\end{array}$ & $\begin{array}{l}45.9 \\
57.5 \\
52.3\end{array}$ & $\begin{array}{l}1.0 \\
7.7 \\
1.1\end{array}$ & $\begin{array}{l}1.8 \\
4.7 \\
2.3\end{array}$ & $\begin{array}{l}91 \\
73 \\
79\end{array}$ \\
\hline \multicolumn{7}{|c|}{$\begin{array}{l}\text { Experiment } 2 \text { - cows fed lucerne chaffage only } \\
\text { DM kinetics for: }\end{array}$} \\
\hline Pasture & 41.4 & 16 & 54.4 & 1.4 & 4.2 & 81 \\
\hline PKE & 26.8 & 10 & 60.5 & 9.3 & 12.6 & 65 \\
\hline $\begin{array}{l}\text { CP kinetics for: } \\
\text { Pasture } \\
\text { PKE }\end{array}$ & $\begin{array}{l}52.3 \\
36.6\end{array}$ & $\begin{array}{c}48 \\
7\end{array}$ & $\begin{array}{l}47.0 \\
60.0\end{array}$ & $\begin{array}{r}1.6 \\
11.2\end{array}$ & $\begin{array}{l}0.7 \\
3.4\end{array}$ & $\begin{array}{l}94 \\
68\end{array}$ \\
\hline $\begin{array}{l}{ }^{1} \mathrm{U}=(100-\mathrm{A}-\mathrm{B}) \\
{ }^{2} \text { Calculated as } \mathrm{ED}=A \\
\text { Coefficient of detern }\end{array}$ & $\begin{array}{l}p) ; k_{p} \\
\text { all fitte }\end{array}$ & $>97 \%$ & & & & \\
\hline
\end{tabular}

greater for pasture (41\%) than for PKE (25 and 27\%) in both experiments. However when PKE was incubated with pasture in Experiment 1, the soluble fraction increased considerably from 25 to $39 \%$. When only PKE was incubated there was very little DM disappearance during the first 5-9 hours (Fig. 1) and the lag was greatest when cows were fed only lucerne chaffage in Experiment 2. Combining pasture and PKE together reduced the lag time to 2.9 hours which was similar to the lag time of bags containing only pasture (1.4 hours). Degradation rates of PKE, pasture and $\mathrm{P}+\mathrm{PKE}$ in Experiment 1 were very similar with values around $12 \% / \mathrm{h}$. However, in Experiment 2 when cows were only fed lucerne chaffage, the degradation rates were slower for PKE $(10 \% / h)$ and faster for pasture $(16 \% / h)$.
After 72 hours of incubation the rumen undegradable residue $(\mathrm{U})$ of the DM was much higher for PKE than pasture, with almost $14 \%$ of the PKE DM being indigestible in the rumen.

\section{CP digestion kinetics}

In both experiments the majority of the soluble CP fraction of pasture was released from the bags, while PKE had only approximately $37 \%$ of soluble CP (Table 2). However, adding pasture to PKE increased the percentage of $\mathrm{CP}$ in the soluble fraction. Results also showed that the slowly degradable "B" fraction of CP had higher values for PKE than pasture, with "B" values being intermediate for $\mathrm{P}+\mathrm{PKE}$. The diet fed to the cows had no effect on the A and B fractions of either PKE or pasture, but it did alter the lag time and the degradation 
Figure 1 In sacco dry matter (DM) fitted degradation curves of palm kernel expeller (PKE) and pasture in Experiment 1 (cows fed lucerne chaffage and PKE) and 2 (cows fed lucerne chaffage). Error bars indicate standard deviations.

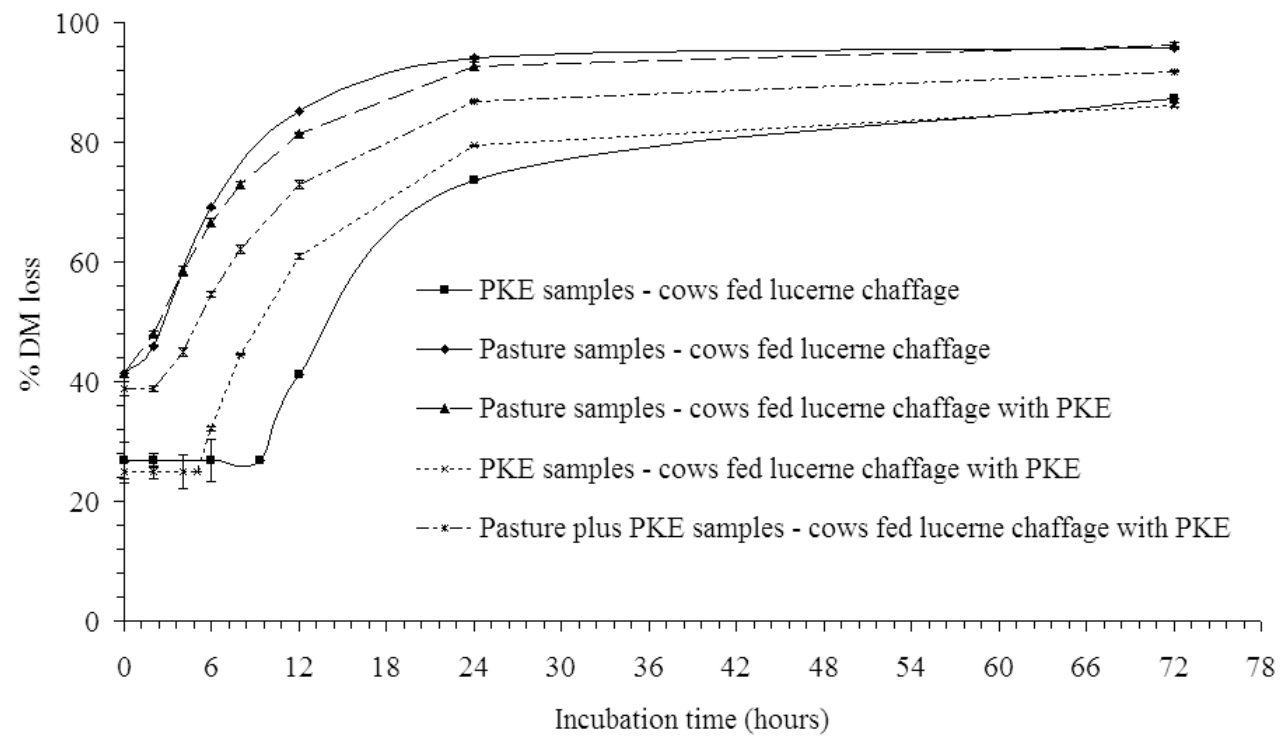

Figure 2 In sacco crude protein (CP) fitted degradation curves of palm kernel expeller (PKE) and pasture in Experiment 1 (cows fed lucerne chaffage and PKE) and 2 (cows fed lucerne chaffage). Error bars indicate standard deviations.

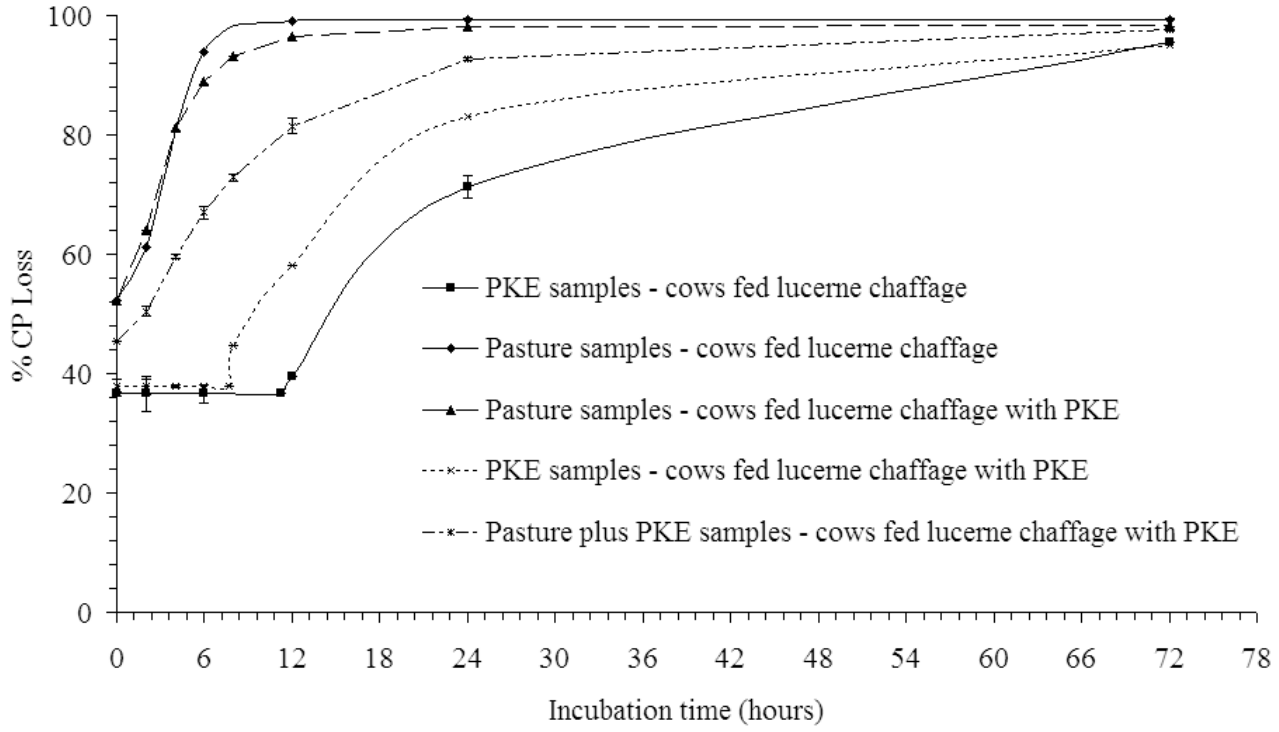

rates.

The disappearance of CP in PKE was delayed for 8 11 hours in Experiment 1 and 2, respectively, compared to only $1-1.6$ hours for pasture and $\mathrm{P}+\mathrm{PKE}$, which was similar to the pattern of DM disappearance. In pasture, the rates of $\mathrm{CP}$ degradation were about three and four times faster than those for DM degradation in Experiment 1 and 2, respectively, whereas the rates of $\mathrm{CP}$ degradation in PKE were slower than those for DM degradation.
Degradation of CP from PKE was slower than pasture (7-10\%/h vs. $34-48 \% / \mathrm{h}$ in both experiments).

In PKE, between $3 \%$ and $4.5 \%$ of CP was not degradable (U) in the rumen for Experiments 1 and 2, respectively, but this value was reduced to $2 \%$ when pasture was incubated with PKE.

\section{Discussion}

The pasture used in this experiment was of moderate 
quality (Waghorn et al. 2007) with high values for NDF and CP and low SSS concentration. The high NDF content suggested that pasture samples were harvested in a mature stage (Chaves et al. 2006). The high CP concentration suggests usage of $\mathrm{N}$ fertilisation in the paddock (Pacheco \& Waghorn 2008) but this cannot be ascertained as the fertilisation history of the paddock from where the samples were collected was unknown. The low concentration of SSS ( $3 \mathrm{~g} / 100 \mathrm{~g} \mathrm{DM})$ obtained in this study could be related to the collection of samples after a cloudy and wet week, as sugar concentrations are totally dependent on the time of day and sunshine for resynthesis of those components (Waghorn et al. 2007).

The CP concentration of PKE (Table 1) found in this study was similar to the values published by Dias et al. (2008) (16.6 g/100g DM) and de Ruiter et al. (2007) $(17.2 \mathrm{~g} / 100 \mathrm{~g} \mathrm{DM})$ in New Zealand, and in the range of values $(15.5$ - $17.7 \mathrm{~g} / 100 \mathrm{~g} \mathrm{DM})$ obtained by Moss \& Givens (1994), O'Mara et al. (1999) and Carvalho et al. (2005). However, the situation with NDF, ADF and fat is less consistent. The concentrations of NDF and ADF obtained in this study (Table 1), and in the studies mentioned above, have shown a significant variation in the fibre components of PKE with values ranging between 67 to 82 and 37 to $57 \mathrm{~g} / 100 \mathrm{~g}$ DM for NDF and ADF, respectively. However, NDF and ADF concentrations of the PKE in this study were similar to that reported by Dias et al. (2008), which was around 73 and $40 \%$, respectively. The fat content of PKE has also varied between studies, although most of the values were consistently above $7 \mathrm{~g} / 100 \mathrm{~g}$ of DM for mechanical extracted PKE, which could indicate that PKE used in this study ( $9 \mathrm{~g} / 100 \mathrm{~g}$ of DM of fat) was produced by mechanical extraction rather than solvent extraction (O'Mara et al. 1999).

The variation in PKE composition could be an effect of different processing of the palm kernel during oil extraction, resulting in a by-product that has variable quality because of the processing method used in its different sources of origin. Also, according to O'Mara et al. (1999), differences in the laboratory procedures used to assess the chemical composition of PKE could cause some variation.

The results from this study have shown that both pasture and PKE A and B fractions were not affected when cows were fed different diets, but the inclusion of PKE in the diet of the animals did appear to affect DM and $\mathrm{CP}$ digestion rates of both PKE and pasture. The introduction of PKE in the diet led to an increase in the degradation rates of PKE and a reduction in the degradation rates of pasture. Other studies have also reported a change in the degradation rate when the diet of the cows was modified (Lindberg 1981; Chaves 2003). The diet offered to the animals used to incubate the samples will affect the in sacco degradation rates of feeds, as demonstrated by Mertens et al. (1998) who showed that feeding cows lucerne-based diets increased the in sacco degradation rates of both lucerne and maize silage, compared to feeding diets containing maize silage only. According to Lopez (2005), the feed samples incubated in the bag should be present in the diet fed to the animals for a more accurate measurement of ruminal degradation of the feed.

Regardless of the differences caused by the diet effect, a large reduction in the lag period when pasture was incubated with PKE samples was measured in our study. According to Lopez (2005), the lag period is partly due to the inability of the rumen microbial population to degrade the substrate, until microbial growth is sufficient to saturate the substrate. Other factors like rate of hydration of the substrate, microbial attachment to feed particles and nutrient limitations also influence the lag period. Therefore, the introduction of pasture with a higher soluble CP fraction could have increased the nitrogen availability within the PKE bags which aided rapid microbial growth and colonisation.

The PKE degradation rates obtained in this study are greater than the values obtained by Woods et al. (2003a, $2003 \mathrm{~b}$ ), which were around 3 and $2 \% / \mathrm{h}$ for $\mathrm{CP}$ and $\mathrm{DM}$ degradability, respectively. However, the degradation rates obtained by those authors were estimated using an exponential model without the lag period, which tends to underestimate the digestion of feeds with large lag periods, like PKE. Although the slow CP degradation rates obtained by Woods et al. (2003a, 2003b) and this study indicate that PKE is a feed with slow rumen degradation.

The PKE percentage of DM (14\%) and CP (4\%) not degraded in the rumen ("U" fraction) is more than double the values published by Woods et al. (2003a, 2003b), which was around 4.6 and $1.8 \%$ for PKE DM and CP, respectively. The chosen model used to fit the observed data could be resonsible for differences in the reported values for A, B and, by difference, the undegradable (U) fraction. This may explain differences between our results (lag included) and those of Woods et al. (2003a, 2003b: no lag included).

Overall the digestion kinetic parameters obtained from this study showed that PKE had slower CP degradation rates than pasture, and by mixing the two feeds it was possible to reduce the degradation rates of the $\mathrm{CP}$ in the bags. As a result, the use of PKE as a supplement for dairy cows could be beneficial if the goal is to reduce total rumen degradability of protein in the diet. The use of large amounts of PKE ( $>50 \%$ of the diet) as a sole supplement, however, could be limited by its maximum voluntary intake (Dias et al. 2008).

The experiments reported herein also showed that cow 
adaptation to PKE is necessary for better microbial growth and digestion, demonstrating the need for adapting animals to the supplement to achieve adequate digestion from its nutrients contained in supplements.

\section{REFERENCES}

AOAC. 2005. Official Methods of Analysis 18th Edition. Ed. Horwitz, W. AOAC International, Gaithersburg, MD, USA.

Burke, J.L.; Waghorn, G.C.; Brookes, I.M.; Attwood, G.T.; Kolver, E.S. 2000. Formulating total mixed rations from forages - defining the digestion kinetics of contrasting species. Proceedings of the New Zealand Society of Animal Production 60: 9-14.

Carvalho, L.P.F.; Melo, D.S.P.; Pereira, C.R.M.; Rodrigues, M.A.M.; Cabrita, A.R.J.; Fonseca, A.J.M. 2005. Chemical composition, in vivo digestibility, $\mathrm{N}$ degradability and enzymatic intestinal digestibility of five protein supplements. Animal Feed Science and Technology 119: 171-178.

Chaves, A.V.; Waghorn, G.C.; Brookes, I.M.; Woodfield, D.R. 2006. Effect of maturation and initial harvest dates on the nutritive characteristics of ryegrass (Lolium perenne L.). Animal Feed Science and Technology 127: 293-318.

Chaves, A.V. 2003. Supplementation of grazing dairy cows with sulla and maize silages in summer. pp. 161193. In: Digestion characteristics of forages, including perennial ryegrass at different stages of maturity, and supplementary feeding for dairy cows grazing pasture. PhD thesis. Massey University, Palmerston North.

Dias, F.N.; Burke, J.L.; Pacheco, D.; Holmes, C. 2008. Brief Communication: The effect of palm kernel expeller as a supplement for grazing dairy cows at the end of lactation. Proceedings of the New Zealand Society of Animal Production 68: 111-112.

Hindle, V.A.; Steg, A.; van Vuuren, A.M.; Vroons-deBruin, J. 1995. Rumen degradation and post-ruminal digestion of palm kernel by-products in dairy cows. Animal Feed Science and Technology 51: 103-121.

Lindberg, J.E. 1981. The effect of basal diet on the ruminal degradation of dry matter, nitrogenous compounds and cell walls in nylon bags. Swedish Journal of Agriculture Research 11: 159-169.

Lopez, S. 2005.In vitro and in situ techniques for estimating digestibility. pp. 87-122. In: Quantitative aspects of ruminant digestion and metabolism. Eds. Dijkstra, J.; Forbes, J.M.; France, J. CABI Publishing, USA.

Lopez, S.; France, J.; Dhanoa, M.S.; Mould, F.; Dijkstra, J. 1999. Comparison of mathematical models to describe disappearance curves obtained using the polyester bag technique for incubating feeds in the rumen. Journal of Animal Science 77: 1875-1888.

MAF, 2007: Pastoral Monitoring Report. http:// nzfsa.org/mafnet/rural-nz/statistics-and-forecasts/ farm-monitoring/2007/pastoral/full-report.pdf.

McDonald, I.M. 1981. A revised model for the estimation of protein degradability in rumen. Journal of Agricultural Science 96: 251-252.

Mertens, D.R.; Weimer, P.J.; Waghorn, G.C. 1998. Inocula differences affect in vitro gas production kinetics. pp. 209-211. In: In vitro techniques for measuring nutrient supply to ruminants, Occasional Publication No. 22. Eds. Deadville, E.R.; Owen, E.; Adesogan, A.T.; Rymer, C.; Huntington, J.A.; Lawerence, T.L.J. British Society of Animal Science.

Moss, A.R.; Givens, D.I. 1994. The chemical composition, digestibility, metabolisable energy content and nitrogen degradability of some protein concentrates. Animal Feed Science and Technology 47: 335-351.

O’Mara, F.P.; Mulligan, F.J.; Cronin, E.J.; Rath, M.; Caffrey, P.J. 1999. The nutritive value of palm kernel meal measured in vivo and using rumen fluid and enzymatic techniques. Livestock Production Science 60: 305-316.

Orskov, E.R.; McDonald, J. 1979. The estimation of protein degradability in the rumen from incubation measurements weighted according to rate of passage. Journal of Agriculture Science 92: 499.

Pacheco, D.; Waghorn, G.C. 2008. Dietary nitrogen definitions, digestion, excretion and consequences of excess for grazing ruminants. Proceedings of the New Zealand Grassland Association 70: 107-116.

Robertson, J.B.; Van Soest, P.J. 1981. The detergent system of analysis. pp. 123-158. In: The Analysis of Dietary Fibre in Food. Eds. James, W.P.T.; Theander, O. Marcel Dekker, NY.

SAS. 2003: SAS/STAT Software. Release 9.11. SAS Institute, Cary, North Carolina, USA.

Waghorn, G.C.; Burke, J.L.; Kolver, E.S. 2007. Principles of feeding value. pp. 35-60 In: Pasture and Supplements for Grazing Animals. Eds. Rattray, P.V; Brookes, I.M.; Nicol, A.M. New Zealand Society of Animal Production, Occasional Publication. Number 14.

Woods, V.B.; O'Mara, F.P.; Moloney, A.P. 2003a. The nutritive value of concentrate feedstuffs for ruminant animals. Part I: In situ ruminal degradability of dry matter and organic matter. Animal Feed Science and Technology 110: 111-130.

Woods, V.B.; O'Mara, F.P.; Moloney, A.P. 2003b. The nutritive value of concentrate feedstuffs for ruminant animals. Part II: In situ ruminal degradability of crude protein. Animal Feed Science and Technology 110: 131-143. 